\title{
ESTUDO DA PRODUÇÃO E ACÚMULO DE PÓ DURANTE A SECAGEM DE POLPA DE GRAVIOLA E LEITE EM LEITO DE JORRO COM ALIMENTAÇÃO INTERMITENTE
}

\author{
T. N. P DANTAS ${ }^{1}$, I. P. MACHADO ${ }^{1}$, M. F. D. MEDEIROS ${ }^{1 *}$ \\ ${ }^{1}$ Universidade Federal do Rio Grande do Norte, Departamento de Engenharia Química, \\ Programa de Pós-Graduação em Engenharia Química \\ *e-mail: mariadefatima@eq.ufrn.br
}

\begin{abstract}
RESUMO
O objetivo principal deste trabalho foi o estudo da modelagem e simulação de produção e acúmulo de pó no leito de partículas inertes no processo de secagem de uma mistura de polpa de graviola e leite em leito de jorro, utilizando alimentação intermitente. Utilizou-se um secador de leito de jorro cônico-cilíndrico, de aço inoxidável com visores em acrílico, base cônica de $60^{\circ}$, diâmetro de $0,18 \mathrm{~m}$, altura de $0,9 \mathrm{~m}$ e diâmetro de entrada do ar de $2,5 \mathrm{x}$ $10^{-2} \mathrm{~m}$. Os experimentos foram executados segundo um planejamento fatorial completo $2^{4}$ com 3 repetições no ponto central. Como variáveis independentes foram consideradas a temperatura do ar na entrada do secador, concentração de leite na mistura, razão de vazão do ar de secagem na entrada e tempo de intermitência, que variaram de 70 a $90^{\circ} \mathrm{C}, 30 \%$ a $50 \%, 1,2$ a 1,5 e 10 a 14 minutos, respectivamente. A partir dos dados de produção e umidade do pó, foi encontrado o modelo estatístico que representava a vazão mássica de pó em função do tempo. Esta equação foi aplicada no balanço de massa para a verificação do acúmulo do material cuja equação diferencial ordinária resultante foi resolvida com a rotina DASSL (Differential Algebraic System Solver). Na análise da simulação, foi constatado que estes modelos, estatístico e diferencial, representam bem a cinética de produção e de acúmulo de pó, respectivamente.
\end{abstract}

\section{INTRODUÇÃO}

A secagem é uma das principais operações de processamento de alimentos, existindo várias técnicas deste processo, sendo mais comum a de aplicação de ar quente (CHRIST, 2006).

$\mathrm{O}$ processamento de alimentos líquidos e pastosos, para a obtenção de pós em leito de jorro, é uma técnica atraente e este interesse se deve as altas taxas de transferência de calor e massa alcançadas (FREIRE et al., 2012 b).
A escolha das condições de processo mais adequadas é fundamental para uma boa eficiência da secagem. As variáveis que exercem maior influência neste processo com partículas inertes são a temperatura, a vazão do ar e a vazão de pasta (CHRIST, 2006). Almeida et al. (2010) acrescenta que também é necessário o conhecimento da fluidodinâmica e dos fenômenos de transferência de calor e massa para o domínio efetivo da técnica.

Estudos demonstram que a secagem de alimentos em secador de leito de jorro é uma 
boa alternativa dado o seu desempenho, baixo custo de construção e a possibilidade de produção de pós alimentares de boa qualidade em pequena quantidade (CUNHA et al., 2006). O pó produzido preserva bem as propriedades químicas e biológicas de alimentos pastosos, como ovo, leite e extratos vegetais (COSTA JR. et al., 2006).

\section{OBJETIVOS}

Motivado por estudos anteriores de secagem de polpas de frutas em leito de jorro realizados no Laboratório de Sistemas Particulados da UFRN, este trabalho propõe o desenvolvimento de um modelo para descrever o comportamento da produção e do acúmulo de pó durante a secagem transiente de uma mistura de polpa de graviola e leite integral em secador de leito de jorro com alimentação intermitente. $\mathrm{O}$ modelo diferencial que descreve o acúmulo de pó no interior do leito de jorro é baseado em balanços de massa.

\section{REVISÃO BIBLIOGRÁFICA}

O mecanismo da secagem de suspensões e o recobrimento de partículas apresentam características semelhantes quando realizadas em leito de jorro. Nestas duas operações a suspensão alimentada recobre as partículas, movimentadas por ar aquecido, formando uma película líquida delgada. $\mathrm{Na}$ secagem, o filme depositado sobre as partículas seca e o atrito entre estas provoca o rompimento do material aderido que é arrastado na forma de pó, enquanto no recobrimento, o sólido permanece unido à partícula após a evaporação do solvente (DONIDA et al., 2007).

Os tempos com e sem alimentação, que compreendem o tempo de intermitência, quando adequadamente ajustados, reduzem a ocorrência de aglomeração das partículas e promovem a estabilidade do jorro durante o processo de secagem. Em estudos de secagem de pastas e suspensões e recobrimento de partículas em leito de jorro ou fluidizado, no início do processo o leito apresenta boas condições de operação, mas com a introdução da suspensão este comportamento fica comprometido. Para evitar o colapso do jorro, principalmente em certas condições de vazão e pressão de atomização da pasta, a alimentação deve ser realizada de forma intermitente (SILVA, 2003).

Costa Jr. et al. (2006) reforçam que este secador ainda apresenta baixa eficiência térmica para aplicações industriais, requerendo modificações no percurso dos gases de escape para reciclá-lo e recuperar o seu calor sensível. Estes fatos fortalecem a necessidade da modelagem e simulação do processo de secagem, visando otimizar as variáveis operacionais e orientar as modificações que resultem na melhoria do seu desempenho.

A modelagem da secagem em leito de jorro com partículas inertes ainda não é bem descrita. A não validação dos modelos se deve, por exemplo, a falta da incorporação dos efeitos da presença da pasta sobre a dinâmica do leito ou das mudanças complexas, como transformação do líquido em pó durante a secagem (FREIRE et al, 2012 b).

Portanto, para ser comercialmente viável, a operação de secagem em leito de jorro ainda precisa de melhorias, como um melhor controle do processo, flexibilidade de desenho para operação com materiais pastosos de composições muito diferentes e ampliação de escala. Necessita-se de estudos bem fundamentados e desenvolvimento de modelos matemáticos versáteis que possibilitem uma simulação confiável para predizer o desempenho do secador sem grandes investimentos em planta piloto ou equipamentos. Os modelos para tais 
aplicações ainda não foram descritos na literatura, provavelmente pela elevada complexidade dos fenômenos envolvidos no processo e dificuldades na obtenção de dados para validação dos mesmos (Freire et al., 2012 a).

\section{MATERIAIS E MÉTODOS}

As pastas utilizadas eram formadas por misturas de polpa artesanal de graviola e leite integral UHT. As concentrações dos componentes da mistura foram definidos em planejamento experimental.

Partículas de polietileno de alta densidade (PEAD) foram utilizadas como material inerte, cujo diâmetro e densidade corresponderam a $3,2 \times 10^{-3} \mathrm{~m}$ e $875 \mathrm{~kg} / \mathrm{m}^{3}$, respectivamente. A porosidade, em leito estático, destas partículas foi 0,386 e a densidade aparente de $537 \mathrm{~kg} / \mathrm{m}^{3}$.

Os ensaios de secagem foram conduzidos no secador de leito de jorro munido de equipamentos periféricos. $\mathrm{O}$ módulo de secagem consta de uma coluna cilíndrica com visor de acrílico - de $18 \mathrm{~cm}$ de diâmetro e $72 \mathrm{~cm}$ de altura - base cônica, com ângulo incluso de $60^{\circ}$, altura de $13 \mathrm{~cm} \mathrm{e}$ diâmetro de entrada de $3 \mathrm{~cm}$, e um ciclone do tipo Lapple que promove a separação e coleta do pó. $\mathrm{O}$ ar é fornecido através de um soprador centrífugo de $7 \mathrm{cv}$, sendo aquecido por um trocador de calor com resistência elétrica de $2000 \mathrm{~W}$ de potência.

Na realização do balanço de massa para avaliação do acúmulo de pó no leito, observou-se a produção uniforme, com tendência ao comportamento linear, em todos os ensaios realizados.

A partir desta observação, ajustou-se o modelo linear, conforme a Equação 1, em que o parâmetro $b$ foi considerado igual a zero, pois não existe massa de pó acumulada no início do processo. $m_{\text {pó acum, }}=a t+b$

Realizando a derivada das equações obtidas pelo ajuste aos dados experimentais, determinou-se a vazão de pó em cada ensaio. As vazões calculadas foram utilizadas como variáveis dependentes de um planejamento experimental fatorial completo $2^{3}$, conforme a Tabela 1.

Tabela 1 - Matriz experimental para os ensaios de secagem.

\begin{tabular}{ccccc}
\hline$E$ & $C(\%)$ & $T\left({ }^{\circ} C\right)$ & $t(\min )$ & $R W_{a r}$ \\
\hline 1 & -1 & -1 & -1 & -1 \\
2 & 1 & -1 & -1 & -1 \\
3 & -1 & 1 & -1 & -1 \\
4 & 1 & 1 & -1 & -1 \\
5 & -1 & -1 & 1 & -1 \\
6 & 1 & -1 & 1 & -1 \\
7 & -1 & 1 & 1 & -1 \\
8 & 1 & 1 & 1 & -1 \\
9 & -1 & -1 & -1 & 1 \\
10 & 1 & -1 & -1 & 1 \\
11 & -1 & 1 & -1 & 1 \\
12 & 1 & 1 & -1 & 1 \\
13 & -1 & -1 & 1 & 1 \\
14 & 1 & -1 & 1 & 1 \\
15 & -1 & 1 & 1 & 1 \\
16 & 1 & 1 & 1 & 1 \\
17 & 0 & 0 & 0 & 0 \\
18 & 0 & 0 & 0 & 0 \\
19 & 0 & 0 & 0 & 0 \\
\hline
\end{tabular}

Fonte: Autor (2015).

Para a vazão de pó, definiu-se um modelo estatístico que é função das condições operacionais concentração de leite, que correspondeu a uma variação de $30 \%$ a $50 \%$ da massa total; temperatura do ar na entrada $(T)$, variando de $70^{\circ} \mathrm{C}$ a $90^{\circ} \mathrm{C}$; tempo de intermitência na alimentação da suspensão $(t)$, com tempo de alimentação fixo e igual a 6 minutos e tempo de intermitência variando de 
10 a 14 minutos; razão de vazão de $\operatorname{ar}\left(R W_{a r}\right)$, cujos valores variaram de 1,2 a 1,5 em relação a vazão de ar de jorro mínimo. As variáveis codificadas utilizadas nos modelos estatísticos estão nas Equações 2 a 5.

$C^{*}=\frac{C-40}{10}$

$T^{*}=\frac{T-80}{10}$

$t^{*}=\frac{T-12}{2}$

$R W_{a r}^{*}=\frac{R W_{a r}-1,35}{0,15}$

Aplicando o balanço de massa de sólido no sistema, encontrou-se a Equação 6 que descreve o acúmulo de pó no leito durante o processo de secagem.

$\frac{d m_{p 0}}{d t}=M=\frac{W_{p o l p a} x_{p o l p a}-W_{p 0} x_{p 0}}{x_{p 0}}$

O balanço de massa foi desenvolvido em linguagem Fortran e o programa calcula a integração da equação diferencial do balanço utilizando a rotina DASSL (Differential Algebraic System Solver).

\section{RESULTADOS E DISCUSSÕES}

A vazão do pó na saída do secador foi determinada através do ajuste linear aos dados de massa de pó produzida em função do tempo, de acordo com a Equação 1. Os coeficientes angulares e os coeficientes de correlação aparecem na Tabela 2.

Os valores de $\mathrm{R}^{2}$ encontrados indicam um ajuste satisfatório entre os valores experimentais e os preditos pela correlação, confirmando a produção constante de pó.
A taxa de produção de pó variou entre $0,018 \mathrm{~g} / \mathrm{min}$ e $0,303 \mathrm{~g} / \mathrm{min}$, com rendimentos mínimo e máximo de, respectivamente, $3,9 \%$ e $42,5 \%$. Os melhores desempenhos foram verificados com maior concentração de leite, baixa temperatura, tempo de intermitência mais curto e vazão do ar mais elevada.

Tabela 2 - Parâmetro estimado e qualidade do ajuste do modelo aos dados de produção de pó.

\begin{tabular}{ccc}
\hline$E$ & Wó $(\mathrm{g} / \mathrm{min})$ & $R^{2}$ \\
\hline 1 & 0,078 & 0,985 \\
2 & 0,181 & 0,995 \\
3 & 0,018 & 0,926 \\
4 & 0,099 & 0,974 \\
5 & 0,024 & 0,988 \\
6 & 0,142 & 0,990 \\
7 & 0,021 & 0,982 \\
8 & 0,036 & 0,955 \\
9 & 0,105 & 0,992 \\
10 & 0,303 & 0,995 \\
11 & 0,069 & 0,993 \\
12 & 0,203 & 0,993 \\
13 & 0,143 & 0,996 \\
14 & 0,155 & 0,998 \\
15 & 0,055 & 0,996 \\
16 & 0,151 & 0,998 \\
17 & 0,087 & 0,988 \\
18 & 0,067 & 0,981 \\
19 & 0,067 & 0,984 \\
\hline
\end{tabular}

Fonte: Autor (2015).

As derivadas das equações lineares resultam em valores constantes que correspondem à vazão de produção de pó. Como a taxa de produção de pó é bastante influenciada pelas condições operacionais da secagem, esta variável de resposta do processo foi equacionada como função das variáveis independentes de operação do secador $-C, T_{g e}, t_{i n t}$ e $W_{a r}-$ a partir de 19 experimentos que compõem um planejamento 
fatorial com delineamento $2^{4}$ e 3 repetições no ponto central.

A equação ajustada aos dados experimentais da vazão de sólido na saída do secador obtida, utilizando as variáveis independentes codificadas, é apresentada na Equação 7.

$$
\begin{aligned}
& W_{p o ́}=0,106-0,031 T^{*}+0,048 C^{*}- \\
& 0,021 t^{*}+0,037 W_{a r}^{*}-0,017 C^{*} t^{*}
\end{aligned}
$$

A significância estatística deste modelo foi avaliada pela análise de variância ANOVA. Utilizando o programa Statistica ${ }^{\circledR}$, realizou-se a comparação da variância dos dados experimentais e a variância resultante do ajuste ao modelo linear, utilizando a distribuição F. $\mathrm{O}$ coeficiente de ajuste encontrado foi igual a $90,52 \%$ e o teste $\mathrm{F}$ da regressão foi igual a 5,9, apresentando uma razão maior que 1 para os $\mathrm{F}$ calculados pelos F tabelados, portanto, a regressão pode ser considerada significativa.

A partir do teste $\mathrm{F}$ da falta de ajuste para os dados de vazão mássica de produção de pó, percebe-se que o modelo possui caráter preditivo, uma vez que a razão entre o $\mathrm{F}$ calculado e o $\mathrm{F}$ tabelado apresentou razão igual a 0,32 .

O gráfico de Pareto, destacando as variáveis significativas para a vazão mássica do pó, está ilustrado na Figura 1.

Analisando o diagrama, todas as variáveis independentes e de forma isolada apresentam os principais efeitos significativos sobre a produção. Avaliando os intervalos considerados nos experimentos, concentração de leite na mistura e vazões do ar mais elevadas disponibilizam maior quantidade de material e aumentam a capacidade de evaporação durante o processo, favorecendo o incremento na vazão de pó. A temperatura mais alta e o tempo de processamento mais longo reduz a vazão de material recuperado. Segundo alguns autores, com o leito aquecido acima da temperatura de transição vítrea da polpa desidratada, a película sobre a partícula inerte se comporta como um material pegajoso o que compromete a remoção de polpa na forma de pó (COLLARES et al., 2004; HOFSETZ, 2007).

Figura 1 - Gráfico de Pareto da vazão mássica de pó na saída do secador.

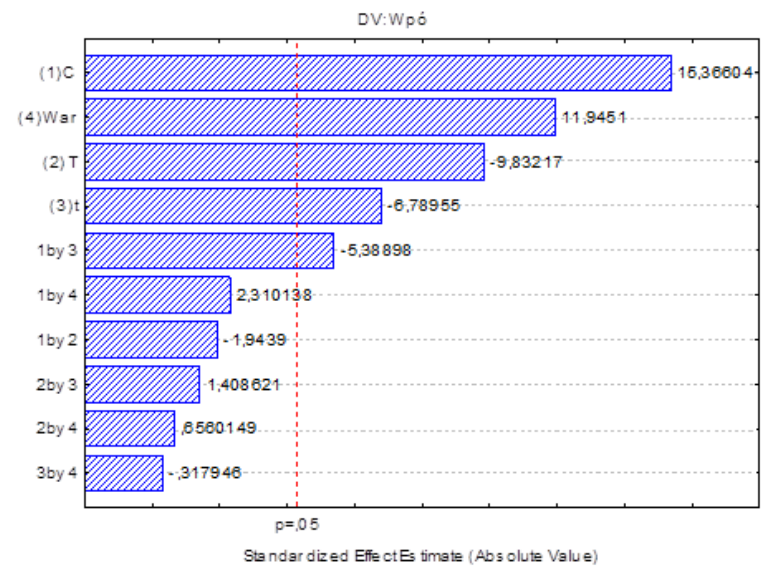

Fonte: Autor (2015).

Nos experimentos, verificou-se que a produção de pó era maior durante o período em que a alimentação da suspensão era interrompida.

Considerando-se os resultados experimentais, a partir das correlações da vazão do pó na saída do secador e a vazão média de alimentação observada em cada experimento, realizou-se o balanço de massa para determinação do acúmulo de pó conforme a Equação 6.

Nas Figuras 2 a 10 são apresentados os dados de produção de pó e do acúmulo de pó no interior do leito e nas paredes do equipamento em função do tempo para os testes realizados com alimentação intermitente da pasta. São incluídos os resultados experimentais e previstos pelo modelo diferencial, para o acúmulo de pó, e pelo modelo estatístico da vazão de pó na saída do secador, para a massa de pó produzida. 
Figura 2 - Comportamento do acúmulo e da produção de pó para os experimentos E1 e E2..

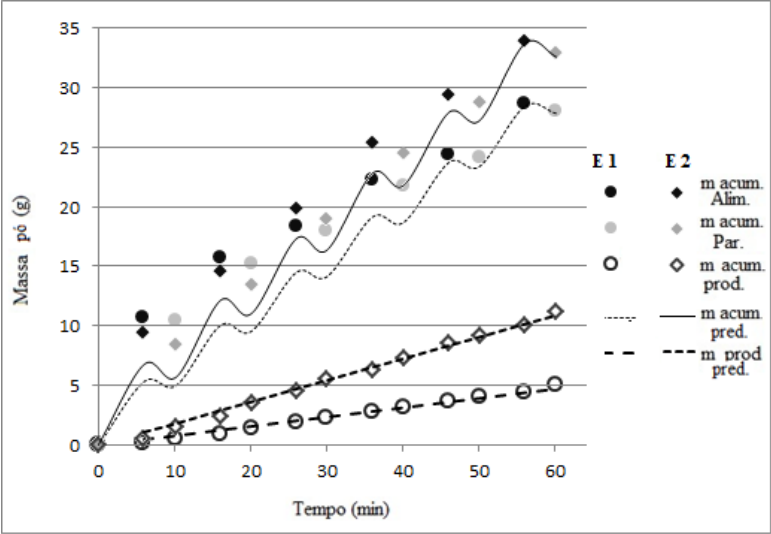

Fonte: Autor (2015).

Figura 3 - Comportamento do acúmulo e da produção de pó para os experimentos E3 e E4.

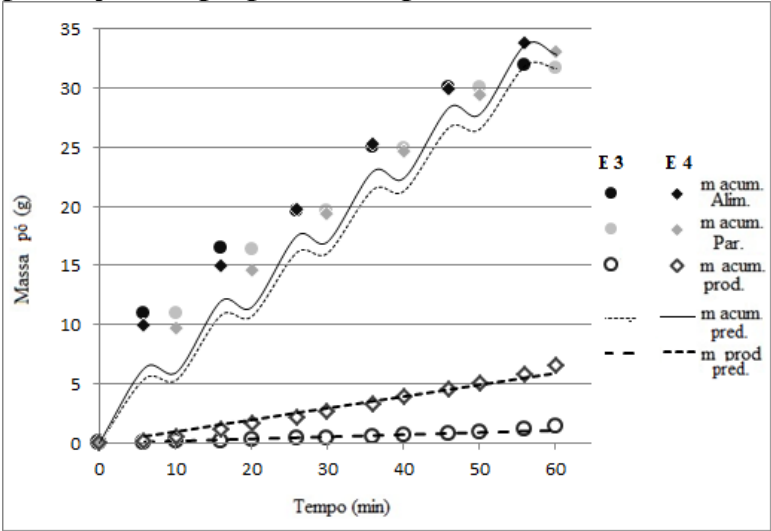

Fonte: Autor (2015).

Figura 4 - Comportamento do acúmulo e da produção de pó para os experimentos E5 e E6.

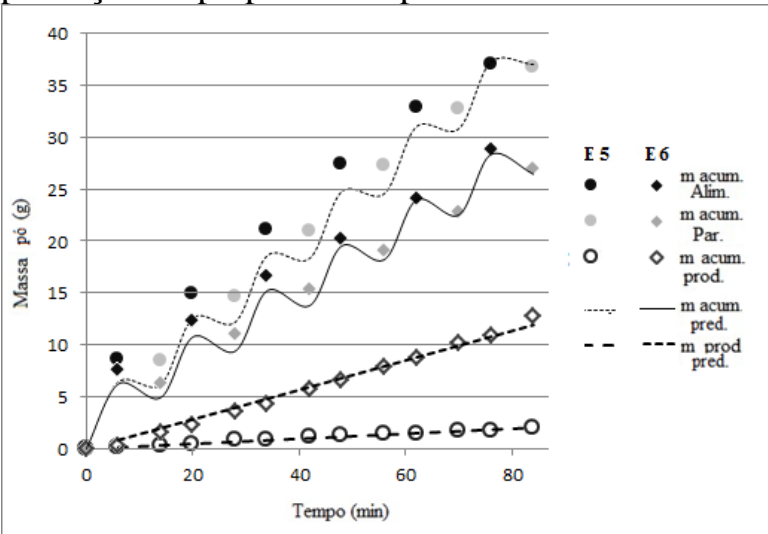

Fonte: Autor (2015).
Figura 5 - Comportamento do acúmulo e da produção de pó para os experimentos E7 e E8.

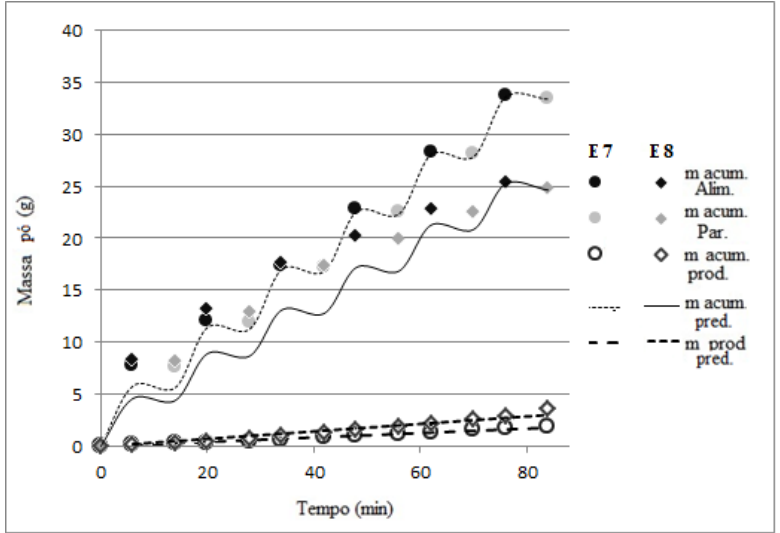

Fonte: Autor (2015).

Figura 6 - Comportamento do acúmulo e da produção de pó para os experimentos E9 e E10.

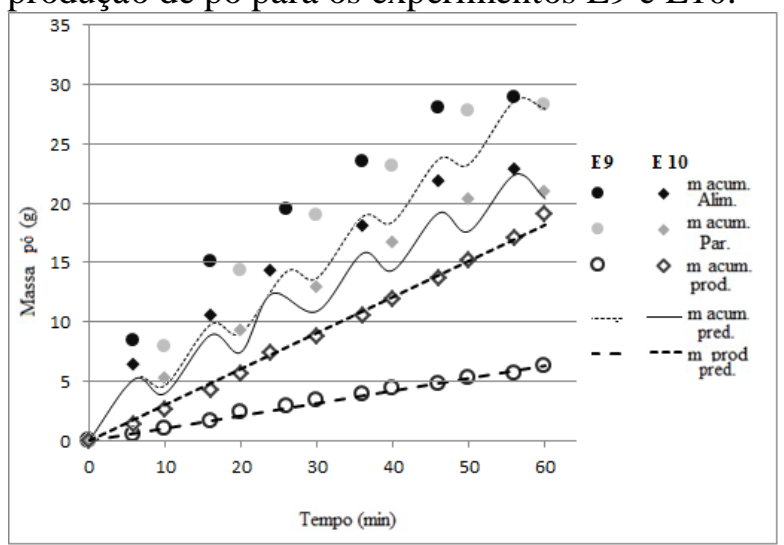

Fonte: Autor (2015).

Figura 7 - Comportamento do acúmulo e da produção de pó para os experimentos E11 e E12.

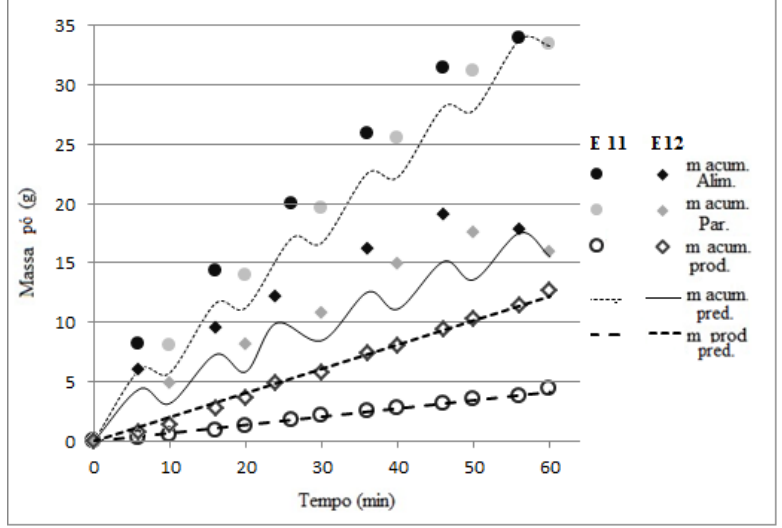

Fonte: Autor (2015). 
Figura 8 - Comportamento do acúmulo e da produção de pó para os experimentos E13 e E14.

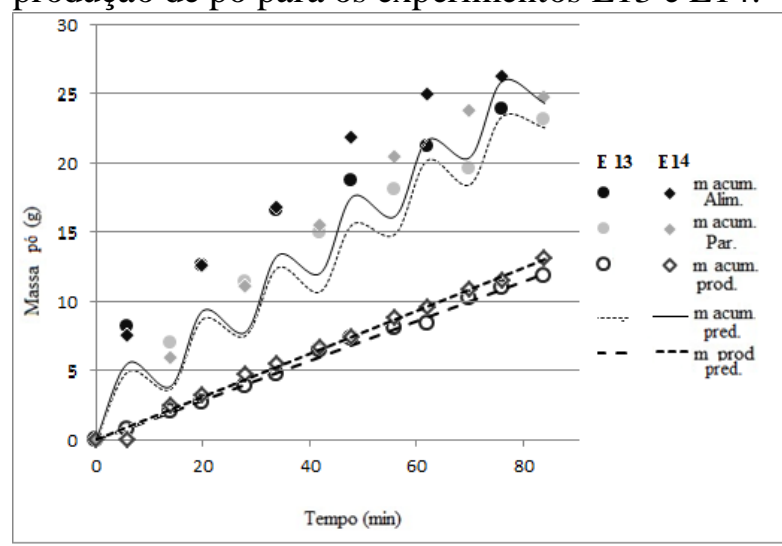

Fonte: Autor (2015).

Figura 9 - Comportamento do acúmulo e da produção de pó para os experimentos E15 e E16.

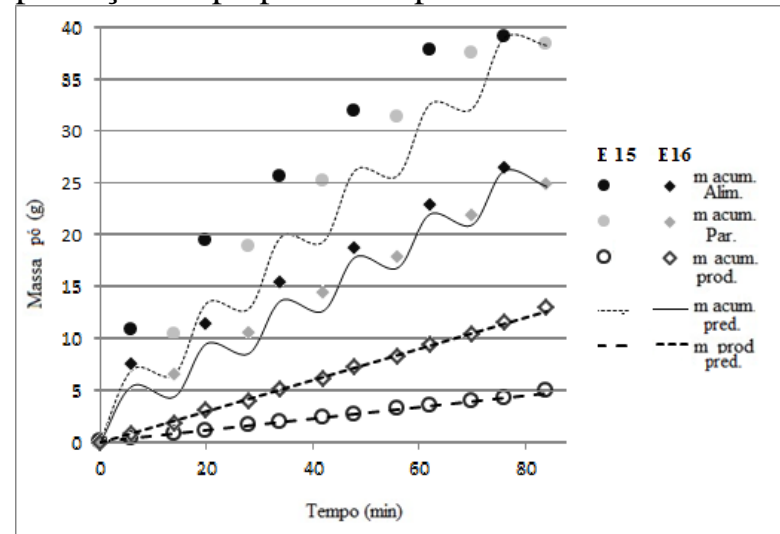

Fonte: Autor (2015).

Figura 10 - Comportamento do acúmulo e da produção de pó para os experimentos E17, E18 e E19.

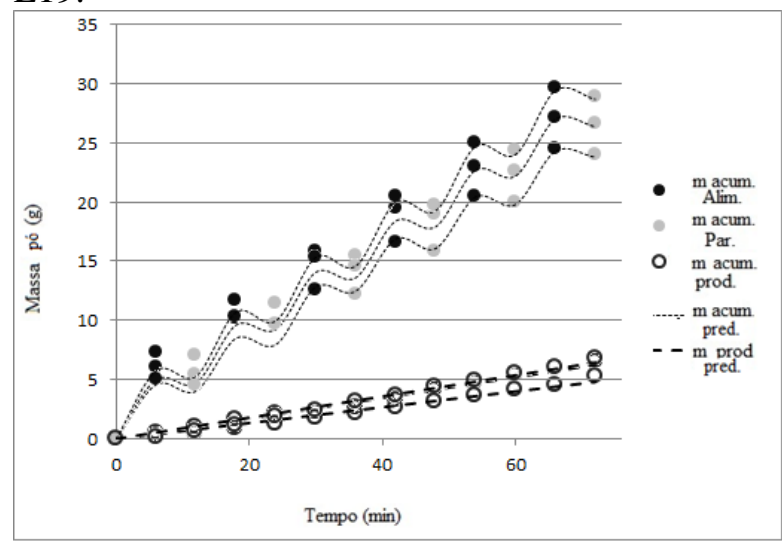

Fonte: Autor (2015).
De acordo com os resultados apresentados, percebe-se, nos experimentos realizados com maior tempo de intermitência, que a temperatura não influenciou na produção de pó quando o sistema foi operado na maior vazão de ar e a mistura possuía maior concentração de leite. Entretanto, observa-se o efeito negativo da temperatura sobre a produção de pó nos ensaios em que a vazão de ar estava na configuração mais baixa, mesmos com concentrações elevadas de leite.

A elevação da velocidade do ar favorece a maior circulação das partículas e choques entre estas, favorecendo o rompimento da película.

Concentrações maiores de leite favoreceram a produção de pó, que é justificada pela sua composição, cuja secagem em leito de jorro tem demonstrado bons resultados (MEDEIROS, 2010).

Nos experimentos realizados a mesma condição de vazão de ar e de concentração de leite, a produção de pó é favorecida nas situações de temperatura mais baixa, fato também verificado por Souza (2009) e Souza Jr. (2012) na secagem de misturas de polpas de frutas em leito de jorro.

As condições operacionais adotadas no ponto central levaram a acumulações e produções de pó intermediárias em relações aos outros experimentos, sendo observada boa reprodutibilidade entre os ensaios.

A massa de sólido acumulada observada experimentalmente e predita pelo modelo refere-se ao pó aderido as partículas inertes e as paredes do equipamento. Isto pode ser confirmado pelas condições de estabilidade do leito de jorro verificadas em todos estes ensaios, com poucas variações na altura do leito e na queda de pressão. Massas aderidas as partículas nestas proporções são suficientes para provocar condições de instabilidade e até colapso do leito. 
Através destas Figuras (Figuras 2 a 10), observa-se a boa concordância das estimativas feitas pelo modelo estruturado no balanço de massa com os dados experimentais obtidos. Os valores dos erros médios relativos, aos dados calculados e observados em cada experimento, calculados a partir da Equação 8 são exibidos na Tabela 3.

$\mathrm{E}=\frac{100}{\mathrm{i}} \sum_{1}^{\mathrm{i}} \frac{\left|\left(\mathrm{m}_{\exp }-\mathrm{m}_{\text {pred }}\right)\right|}{\mathrm{m}_{\exp }}$

As estimativas apresentaram, em relação aos dados experimentais, erros satisfatórios, conforme a Tabela 3 .

Tabela 3 - Erros médios na predição do acúmulo e produção de pó e na predição das massas finais, acumuladas e produzidas.

\begin{tabular}{lcccc}
\hline & $\begin{array}{c}\text { Eacum } \\
(\%)\end{array}$ & $\begin{array}{c}\text { E prod } \\
(\%)\end{array}$ & $\begin{array}{c}\text { E final } \\
\text { acum }(\%)\end{array}$ & $\begin{array}{c}\text { E final } \\
\text { prod }(\%)\end{array}$ \\
\hline E1 & 20,67 & 15,13 & 0,60 & 6,35 \\
E2 & 10,81 & 8,67 & 0,97 & 2,19 \\
E3 & 8,12 & 21,20 & 1,41 & 6,68 \\
E4 & 10,87 & 15,8 & 0,49 & 10,94 \\
E5 & 9,98 & 11,06 & 0,61 & 1,92 \\
E6 & 6,59 & 12,38 & 0,21 & 6,68 \\
E7 & 1,77 & 13,46 & 0,20 & 6,78 \\
E8 & 21,89 & 15,35 & 0,46 & 11,94 \\
E9 & 23,43 & 5,93 & 0,90 & 1,01 \\
E10 & 14,02 & 6,40 & 2,76 & 4,97 \\
E11 & 13,36 & 9,46 & 0,35 & 4,50 \\
E12 & 24,20 & 9,34 & 2,57 & 3,79 \\
E13 & 22,79 & 1,26 & 1,27 & 0,88 \\
E14 & 22,34 & 3,84 & 2,35 & 1,97 \\
E15 & 21,57 & 2,86 & 1,31 & 0,52 \\
E16 & 3,30 & 12,69 & 2,78 & 1,16 \\
E17 & 8,37 & 6,35 & 0,75 & 3,52 \\
E18 & 13,94 & 0,12 & 8,4 & 0,011 \\
E19 & 16,19 & 8,66 & 5,08 & 0,67 \\
\hline
\end{tabular}

No geral, o erro da massa final tende a ser menor que o erro médio, pois no decorrer da secagem podem ocorrer oscilações que se compensem, resultando, ao final do processo, em massas produzidas e acumuladas mais próximas do valor experimental. Ressalta-se também que, no modelo diferencial do acúmulo de sólido, considera-se a vazão média de alimentação, enquanto os valores experimentais são calculados utilizando a vazão real desta variável no intervalo em análise.

Outro fator que influencia o balanço de massa é a estabilidade na vazão de entrada da pasta durante o período de alimentação. Em todos os experimentos, ocorreram variações na alimentação da suspensão durante o período em que esta era introduzida no secador. O modelo proposto não prevê as variações na vazão de alimentação da pasta e é executado considerando uma vazão média. Por esta razão, nos ensaios com menores oscilações de vazão de alimentação, verificam-se menores erros médios relativos na estimação da produção e acúmulo de pó durante a secagem.

O modelo linear da produção de pó não é diretamente dependente da vazão de pasta, mas a instabilidade da vazão acarretou desvios na linearidade da produção de material. Os erros tenderam a valores elevados no início do processo, onde se verificaram os maiores desvios e menores massas, mas nos experimentos com bom controle da vazão da pasta no período da alimentação, os erros de produção apresentaram valores consideravelmente mais baixos.

\section{CONCLUSÕES}

Os modelos propostos conseguiram predizer o acúmulo e a produção de pó na saída do secador durante o processo de 
secagem com boa concordância com os dados experimentais.

A utilização das equações empíricas, vazão de pó na saída do secador, limita a utilização dos modelos para estes casos específicos. Novos estudos devem ser realizados, com o objetivo de reduzir a dependência do modelo em relação às equações empíricas, em que o foco será a investigação da influência das propriedades físicas e da composição da suspensão na predição destes parâmetros.

\section{NOMENCLATURA}

$a$ - parâmetro do modelo linear

Alim - período de alimentação

acum - acumulado

$b$ - parâmetro do modelo linear

$E-$ Erro (\%)

$m$ - massa de pó $(\mathrm{kg})$

Par - Período de parada de alimentação

pred-predito

prod-produzido

$Q$ - Vazão de alimentação ( $\mathrm{mL} / \mathrm{min})$

$T$ - Temperatura do ar na entrada $\left({ }^{\circ} \mathrm{C}\right)$

$t$ - Tempo de intermitência na alimentação da suspensão (min)

$W$ - vazão mássica $(\mathrm{kg} / \mathrm{s})$

$R W_{a r}$ - Razão de vazão de ar de secagem

$x$ - fração mássica de sólido

\section{REFERÊNCIAS}

ALMEIDA, A. R. F., FREIRE, F. B., FREIRE, J. T. Transient analysis of pasty material drying in a spouted bed of inert particles. Drying Technology, v.28, n.3, p.330-340, 2010.

CHRIST, D. Secagem de clara de ovo em leito de jorro fluidizado bidimensional. 180f. Tese (Doutorado em Engenharia de Alimentos), Universidade Estadual de Campinas, Campinas, 2006.
COLLARES, F.P., J.R.D. FINZER, T.G. KIECKBUSCH. Glass transition control of the detachment of food pastes dried over glass plates. Journal of Food Engineering, v. 61, p. 261-267, 2004.

COSTA JR., E. F.; FREIRE, F. B.;FREIRE, J. T.; PASSOS, M. L. Spouted Beds of Inert Particles for Drying Suspension. Drying Technology, v.24, n.3, p.315-325, 2006.

CUNHA, R. L.; CRUZ, A. G.; MENEGALLI, F. C. Effects of operating conditions on the quality of mango pulp dried in a spout fluidized bed. Drying Technology, v.24, n.4, p.423-432, 2006.

DONIDA, M.W.; ROCHA, S.C.S.; CASTRO, B. D.; MARQUES, A. M. Coating and drying in spouted bed: influence of the liquid-particle work of adhesion. Drying Technology, v.25, n.10, p.319-326, 2007.

FREIRE, J.T.; FERREIRA, M.C.; FREIRE, F.B.; NASCIMENTO, B.S. A review of paste drying with inert particles. Drying Technology, v. 30, p. 330-341, 2012a.

FREIRE, J. T; FREIRE, F. B.; FERREIRA, M. C.; NASCIMENTO, B. S. A hybrid lumped parameter/neural network model for spouted bed drying of pastes with inert particles. Drying Technology, v. 30, n. 6, p. 1342-1353, 2012b.

HOFSETZ, K.; LOPES, C.C.; HUBINGER, M.D.; MAYOR, L.; SERENO, A.M. Changes in the physical properties of bananas on applying HTST pulse during air-drying. Journal of Food Engineering, v.83, p.531540, 2007.

SILVA, O. S.; ROCHA, S. C. S.; MARSAL, S. C. The influence of the moisture content of microcrystalline cellulose on the coating 
process in a fluidized bed. Brazilian Journal Chemical Engineering, v. 21, n. 2, p. 325333, 2004.

SOUZA JR., J. S. Secagem do resíduo industrial da acerola em leito de jorro: estudos fluidodinâmicos e análise do desempenho do secador. 125f. Dissertação (Mestrado em Engenharia Química), Universidade Federal do Rio Grande do Norte, Natal, 2012.

SOUZA, J. S. Secagem de misturas de polpa de frutas tropicais em leito de jorro. 157f. Tese (Doutorado em Engenharia Química), Universidade Federal do Rio Grande do Norte, Natal, 2009.

\section{AGRADECIMENTOS}

À CAPES, pelo apoio financeiro. 